\title{
Iatrogenic dural arteriovenous fistula after surgical resection of a ruptured brain arteriovenous malformation
}

Sir,

Iatrogenic dural arteriovenous fistulas (DAVFs) have been reported after cranial surgery, including burr holes and craniotomies, although in very limited number of cases. ${ }^{[1]}$ Intracranial hemorrhage is the most common presentation of brain arteriovenous malformations (AVMs), and microsurgical resection is one of the mainstays of therapy for these uncommon and challenging cerebrovascular lesions. ${ }^{[2]}$ However, an iatrogenic DAVF after AVM resection has not been previously described. We report 
a unique case of a patient who developed an iatrogenic DAVF several months following craniotomy for resection of an acutely ruptured AVM.

A 26-year-old male presented with headache and left-sided weakness. Brain computed tomography (CT) showed a large right frontal intracerebral hemorrhage ( $\mathrm{ICH}$ ) with intraventricular extension [Figure 1a]. CT angiography (CTA) showed an ill-defined AVM nidus supplied by a medial frontal branch of the anterior cerebral artery, with superficial venous drainage into the superior sagittal sinus and deep venous drainage into the thalamostriate vein, which was consistent with a ruptured Spetzler-Martin Grade II AVM. We emergently performed a craniotomy for ICH evacuation, AVM resection, and external ventricular drain placement. Postoperative cerebral angiography showed no evidence of residual arteriovenous shunting [Figure $1 b$ and $c$ ]. The patient had an uncomplicated hospital course and made a complete postoperative neurological recovery.

The patient subsequently presented 5 months after AVM resection with a new-onset seizure. Brain CTA showed mildly prominent frontal lobe vessels. Further characterization with cerebral angiography, performed 9 months after AVM resection, showed a Borden Type III DAVF supplied by a frontal branch of the middle meningeal artery, with venous drainage directly into a medial frontal cortical vein through

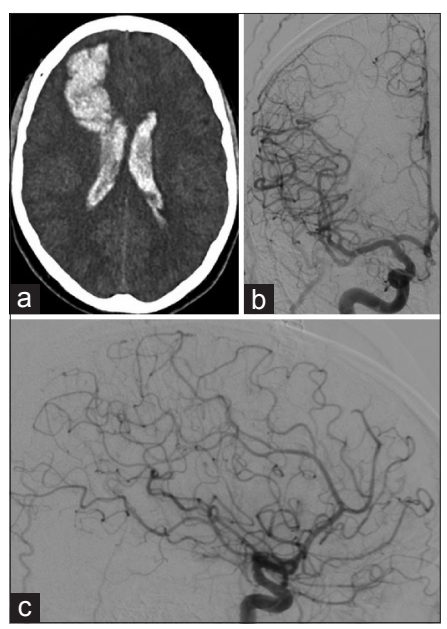

Figure 1: (a) Preoperative brain computed tomography, axial view, shows a right frontal intracerebral hematoma, measuring $6.5 \mathrm{~cm} \times 3.0 \mathrm{~cm} \times 2.5 \mathrm{~cm}$, with deep extension resulting in intraventricular hemorrhage from a ruptured Spetzler-Martin Grade II arteriovenous malformation (poorly defined nidus on computed tomography angiography). The patient underwent an emergent right frontal craniotomy for hematoma evacuation and ruptured arteriovenous malformation resection. Postoperative cerebral angiography, (b) anteroposterior and (c) lateral views of a right internal carotid artery injection, shows no residual arteriovenous shunting, consistent with complete arteriovenous malformation obliteration a diffuse network of vessels underneath the prior craniotomy [Figure 2a and b]. The DAVF was embolized from a transarterial approach using precipitating hydrophobic injectable liquid. The patient had a seizure after the embolization procedure, without any accompanying radiologic evidence of complications. At 3 months clinical follow-up, the patient's seizures were controlled with anticonvulsant therapy, and he had returned to work (modified Rankin scale of 1 ). Postembolization angiography, performed 6 months after the procedure, showed durable occlusion of the DAVF [Figure 2c and $d$ ].

Ruptured AVMs are generally treated on a semi-elective basis. ${ }^{[3]}$ Specifically, the acute hemorrhage is allowed to resolve in order to facilitate angiographic delineation of the nidus and surgical dissection or radiosurgical targeting. However, in the case of a life-threatening $\mathrm{ICH}$, emergent surgical intervention may be necessary. To the best of our knowledge, this case represents the first report of an iatrogenic DAVF after a craniotomy for AVM resection. Although the occurrence of iatrogenic DAVFs in surgically treated AVM patients is exceedingly rare, it emphasizes the necessity of rigorous, long-term angiographic, clinical follow-up of AVM patients. An investigation for residual or recurrent arteriovenous shunting may be warranted in AVM patients who develop de novo seizures in a delayed fashion after complete nidal obliteration. ${ }^{[4,5]}$

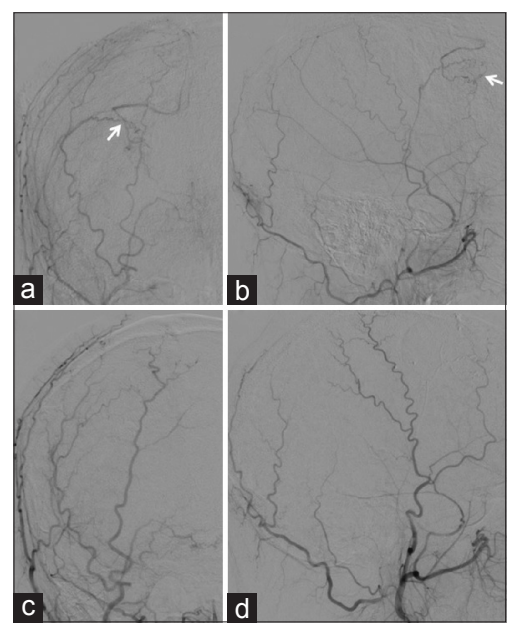

Figure 2: Cerebral angiography performed 9 months after the patient's arteriovenous malformation resection, (a) anteroposterior and (b) lateral views of a right external carotid artery injection, shows a dural arteriovenous fistula supplied by a frontal branch of the right middle meningeal artery and draining into a medial frontal cortical vein (Borden Type III) through a diffuse network of vessels under the previous craniotomy (arrow). The dural arteriovenous fistula was embolized with precipitating hydrophobic injectable liquid from a transarterial route. Follow-up cerebral angiography performed 6 months after the embolization procedure, (c) anteroposterior, and (d) lateral views of a right external carotid artery injection, shows no residual arteriovenous shunting, consistent with durable occlusion of the dural arteriovenous fistula 


\section{Financial support and sponsorship}

Nil.

\section{Conflicts of interest}

There are no conflicts of interest.

\section{Dale Ding ${ }^{1,2}$, Stefan Brew ${ }^{3}$, Ben McGuinness 3 , Edward W. Mee ${ }^{2}$}

${ }^{1}$ Department of Neurosurgery, University of Virginia, Charlottesville, VA 22908, USA, Departments of ${ }^{2}$ Neurosurgery and ${ }^{3}$ Radiology, Auckland City Hospital, Auckland 1142, New Zealand

Address for correspondence: Dr. Dale Ding, Department of Neurosurgery, University of Virginia, P. O. Box: 800212, Charlottesville, VA 22908, USA. E-mail: dmd7q@hscmail.mcc.virginia.edu

\section{References}

1. Vadivelu S, Xin X, Loven T, Restrepo G, Chalif DJ, Setton A. Iatrogenic dural arteriovenous fistula and aneurysmal subarachnoid hemorrhage. Neurosurg Focus 2012;32:E1.

2. Ding D, Liu KC. Predictive capability of the Spetzler-Martin versus supplementary grading scale for microsurgical outcomes of cerebellar arteriovenous malformations. J Cerebrovasc Endovasc Neurosurg 2013;15:307-10
3. Ding D, Yen CP, Starke RM, Xu Z, Sheehan JP. Radiosurgery for ruptured intracranial arteriovenous malformations. J Neurosurg 2014;121:470-81.

4. Chen CJ, Chivukula S, Ding D, Starke RM, Lee CC, Yen CP, et al. Seizure outcomes following radiosurgery for cerebral arteriovenous malformations. Neurosurg Focus 2014;37:E17.

5. Ding D, Quigg M, Starke RM, Yen CP, Przybylowski CJ, Dodson BK et al. Cerebral arteriovenous malformations and epilepsy, part 2: Predictors of seizure outcomes following radiosurgery. World Neurosurg 2015;84:653-62.

This is an open access article distributed under the terms of the Creative Commons Attribution-NonCommercial-ShareAlike 3.0 License, which allows others to remix, tweak, and build upon the work non-commercially, as long as the author is credited and the new creations are licensed under the identical terms.

\begin{tabular}{|l|l|}
\hline \multicolumn{2}{|c|}{ Access this article online } \\
\hline Quick Response Code: & Website: \\
\hline & www.ruralneuropractice.com \\
\hline
\end{tabular}

How to cite this article: Ding D, Brew S, McGuinness B, Mee EW. latrogenic dural arteriovenous fistula after surgical resection of a ruptured brain arteriovenous malformation. J Neurosci Rural Pract 2016;7:604-6. 